Marcelo Forcato, Joner Dias, Anelise Dalberto, Guilherme Ortiz *

\title{
A borracha sintética de chinelos descartados no design de produtos
}

Marcelo dos Santos Forcato Mestre em Design; Universidade Estadual de Maringá <msforcato2@uem.br>

Joner de Lima Dias

Especialista; Universidade Estadual de Maringá <jldias2@uem. br>

Anelise Guadagnin Dalberto Mestre em Arquitetura; Universidade Estadual de Maringá <agdalberto2@uem.br>

Guilherme Clausem Ortiz Graduado em Design; Universidade Estadual de Maringá <guilhermeclausemortiz93@gmail.com>
Resumo Este artigo apresenta resultados obtidos por projeto de pesquisa que objetivou investigar e desenvolver material proveniente de resíduos sólidos de borracha sintética de chinelos descartados além de sugerir aplicações em design de produto. Com a utilização deste resíduo em estado de pó, foram realizados testes com aglutinantes artificiais e vegetais que formaram alternativas de materiais que posteriormente foram submetidos a testes químicos e físicos.

Como resultados, obtiveram-se três materiais experimentais que utilizam aglutinantes de baixo impacto ambiental. Neste artigo será apresentado um dos materiais obtidos bem como sugestão de aplicação no design de superfície.

Palavras chave Resíduo sólido, borracha de chinelos descartados, material experimental, design de superfície.

\section{Synthetic Rubber from Discarded Slippers in Product Design}

Abstract This article presents results obtained by a research project that aimed to investigate and develop material from solid waste of synthetic rubber of discarded slippers and to suggest applications in product design. With the use of this residue powdered, tests were carried out with artificial and vegetable binders that formed alternative materials that were subsequently subjected to chemical and physical tests. As results, three experimental materials were obtained using low environmental impact binders. This article will present one of the materials obtained as well as suggestion of application in the surface design.

Keywords Solid waste, rubber discarded slippers, experimental material and surface design. 


\section{Introdução}

A borracha, em todas as suas tipologias, é um material amplamente utilizado nos produtos industriais atuais. Dentre os mais utilizados estão pneus, revestimentos de cabos elétricos e eletrônicos, recipientes, calçados, brinquedos, produtos para vedação, luvas e outros produtos de uso individual. As principais características que a difere dos demais materiais são o potencial elevado de estiramento e sua resiliência (LIMA, 2006). Papautsky (2003) enfatiza ainda a resistência à abrasão, resistência à corrosão e impermeabilidade, além do material permitir mistura com outras substâncias ou materiais para melhorar seu desempenho.

As borrachas podem ser classificadas como borracha natural e borracha sintética. Tratase como borracha natural àquela produzida através da retirada da seiva da árvore seringueira. Este material foi amplamente utilizado possibilitando o desenvolvimento econômico da região Norte do Brasil a partir do século XIX. As borrachas sintéticas são elastômeros obtidos pela síntese da borracha, ou seja, é uma borracha artificial. Sua descoberta foi em 1875, porém, a produção em massa só foi iniciada a partir da Segunda Guerra Mundial, com o crescimento da demanda por este material. Suas características são inferiores às da borracha natural, porém, sua produção é mais rápida, tornando o material mais barato (MUCAMBO, 2015).

Segundo Statista (2016), a produção de borracha sintética vem crescendo ao longo dos anos (Figura 1).

Figura 1 - Produção global de borracha sintética entre os anos de 2000 e 2014.

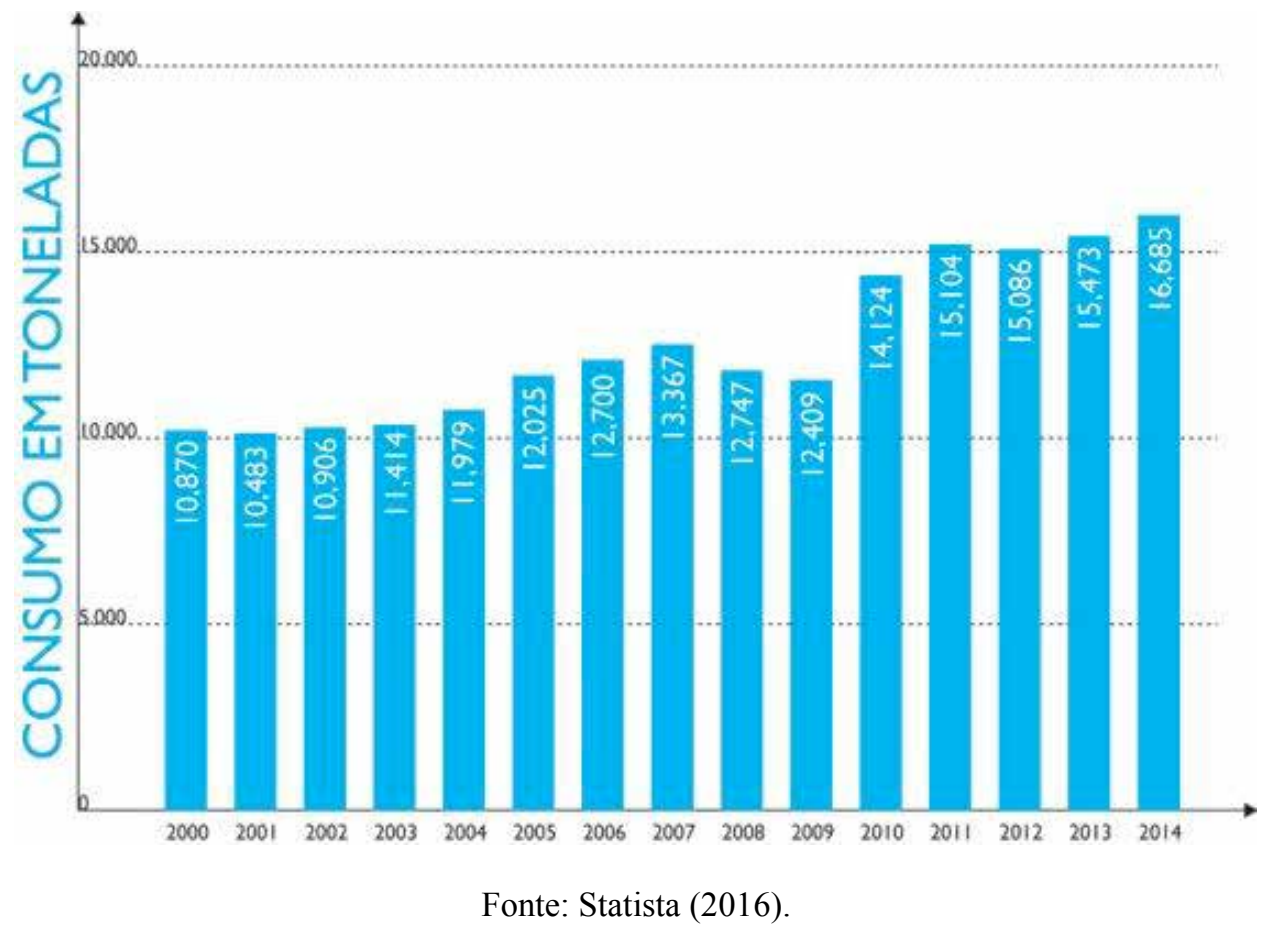

Acredita-se que um dos motivos deste crescimento seja a facilidade na produção da borracha sintética se comparada com a da borracha natural. Entretanto, o aumento da produção da borracha sintética, mostra uma situação de demanda que afeta diretamente o meio ambiente. 
A borracha sintética é derivada do petróleo e sabe-se que o petróleo é um bem não renovável. Soma-se a isto o fato deste material, quando descartado, demorar vários anos para ser absorvido pela natureza (MUCAMBO, 2015).

Relacionado ao volume de produção setorial da borracha, em 2013, do total de borracha sintética produzida, $68 \%$ foi utilizada pela indústria de pneus, $9 \%$ para produção de artigos mecânicos, $8 \%$ na produção de outros produtos automotivos, $5 \%$ pela indústria de calçados, $5 \%$ pela construção civil, sendo o restante para produção de outros produtos diversos (GLOBAL RUBBER MARKETS, 2014).

Mesmo havendo a possibilidade de reciclagem da borracha sintética, nota-se um atraso do Brasil se comparado a outros países. Tal atraso é mais significativo se for desconsiderada a reciclagem de pneus focando-se nos outros produtos fabricados em borracha. No Brasil, o parque industrial de produção de borracha está defasado. Para facilitar a reciclagem uma modernização tecnológica e da gestão da produção deveria ser feita, facilitando, portanto, o reaproveitamento. As novas gerações vêm aumentando a sua preocupação com o impacto dos objetos no meio ambiente, e consequentemente suas decisões de compra podem ser influenciadas por tal preocupação. Além disso, o descarte de produtos de borracha deve ser levado a sério pela indústria que deve investir na reciclagem de seus produtos e pensar em formas alternativas para o ciclo de vida de produtos que atingiram o final de sua vida útil (NUNES, 2015).

Com relação à indústria de borracha, inclusive à produção de pneus, algumas estatísticas apontadas por Brown (2008) apud Forrest (2014) assinalam que o total de borracha reciclada mundialmente quando os produtos chegam ao fim da vida útil está entre $3 \%$ e $15 \%$; com relação ao montante de borracha reutilizada de alguma forma os números ficam entre 5\% e 23\% (BROWN, 2008 apud FORREST, 2014).

Tratando-se da indústria brasileira de pneus, 90\% dos pneus são reaproveitados, entretanto, existe um atraso se for desconsiderada a reciclagem de outros produtos feitos de borracha. O montante de resíduos gerados pela indústria de artefatos de borracha é jogado em aterros e poucas indústrias desse setor se preocupam com os refugos, fato que contribui para a falta de um dimensionamento e impactos dos produtos de borracha, com exceção dos pneus. Calcula-se que o montante de refugo de borracha no Brasil esteja entre $15 \%$ e $20 \%$, valor considerado extremamente elevado (NUNES, 2015).

Existe também a questão do desperdício nas indústrias, nos processos produtivos, mostrando a necessidade de uma revisão na cadeia de produção e o incentivo da criação de ciclos que evitem o desperdício de material. Segundo o autor, processos como moldagem por injeção geram um desperdício que fica entre $30 \%$ e $50 \%$. Já o processo de extrusão gera um desperdício que varia de $2 \%$ a $5 \%$ e o desperdício em processos finais como estamparia (de peças como juntas em lâminas de borracha) está entre $20 \%$ e $40 \%$ aproximadamente (BROWN, 2008 apud FORREST, 2014).

Soma-se a isto o fato do setor calçadista ser destaque na economia brasileira. O país é o principal produtor no continente americano e sua produção é principalmente voltada para o mercado interno. Entretanto, o país busca melhorar suas indústrias calçadistas e expandir seu comércio para combater a concorrência do mercado asiático (GUIDOLIN et. al., 2010).

$\mathrm{Na}$ década de 1990, o setor calçadista brasileiro sofreu com a inserção do mercado asiático que oferecia um produto mais barato. Com isso, muitas empresas calçadistas no Brasil mudaram suas fábricas para o Nordeste devido a incentivos fiscais e custo da mão-deobra reduzida. Como resultado, foi estabelecido no Brasil dois modelos para o setor calçadista: um deles é mais tradicional localizado no Sudeste e Sul do Brasil, onde as 
produções são feitas por pequenas e médias empresas, voltadas a públicos reduzidos sendo que sua produção não possui extrema abrangência; o outro modelo, concentrado no Nordeste, compreende empresas de grande porte que buscam nessa região ferramentas para concorrer com produtos internacionais. No gráfico abaixo (Figura 2) é possível ver essa diferença nos dois modelos ao analisar a relação dos estados com o porte das empresas (em número de empregados) (GUIDOLIN et. al., 2010).

Figura 2 - Principais estados brasileiros produtores de calçados em 2008.

\begin{tabular}{|c|c|c|c|}
\hline \multicolumn{4}{|c|}{$\begin{array}{l}\text { ESTADOS BRASILEIROS } \\
\text { PRODUTORES DE CALÇADOS }\end{array}$} \\
\hline STADOS & EMPREGADOS & ESTABELECIMENTOS & $\begin{array}{l}\text { SSTADOS } \\
\text { ESTABELECAMENTOS }\end{array}$ \\
\hline $\begin{array}{l}\text { RO GRUNDE } \\
\text { DO SUl. }\end{array}$ & 106.225 & 3.285 & 32,3 \\
\hline CEARA & 49.561 & 287 & 172.7 \\
\hline SHOPAULO & 47.732 & 2.912 & 16.4 \\
\hline BAHIA. & 31.408 & 132 & 237,9 \\
\hline MINAS GERALS & 24.654 & 1.572 & 15.7 \\
\hline PARAieA & 12.077 & 114 & 105,9 \\
\hline $\begin{array}{l}\text { SANTA } \\
\text { CATARINA }\end{array}$ & 7.143 & 339 & 21.1 \\
\hline sengire & 3.364 & 14 & 240.3 \\
\hline PARANÁ & 2.608 & 149 & 17,5 \\
\hline PERNANBUCO & 1.613 & 61 & 26,4 \\
\hline cous & 1.529 & 209 & 7,3 \\
\hline DEMAIS ESTADOS & 5.326 & 238 & 223,2 \\
\hline TOTAL & 293.240 & 9.312 & 31,5 \\
\hline
\end{tabular}

Fonte: RAIS [Brasil (2009)].

Em escala internacional, o Brasil é o terceiro maior produtor de calçados, sendo que em 2008 o país produziu 804 milhões de calçados e $80 \%$ da quantidade produzida foi consumida internamente. Além disso, a produção brasileira é muito concentrada em calçados de plástico e borracha com enfoque para os chinelos de plástico/borracha que é o único setor calçadista brasileiro que mostrou crescimento em anos anteriores em relação aos outros tipos de calçados como pode ser visto na Figura 3 (GUIDOLIN et. al., 2010). 
Figura 3 - Produção brasileira por tipo de calçado de 2003 a 2007.

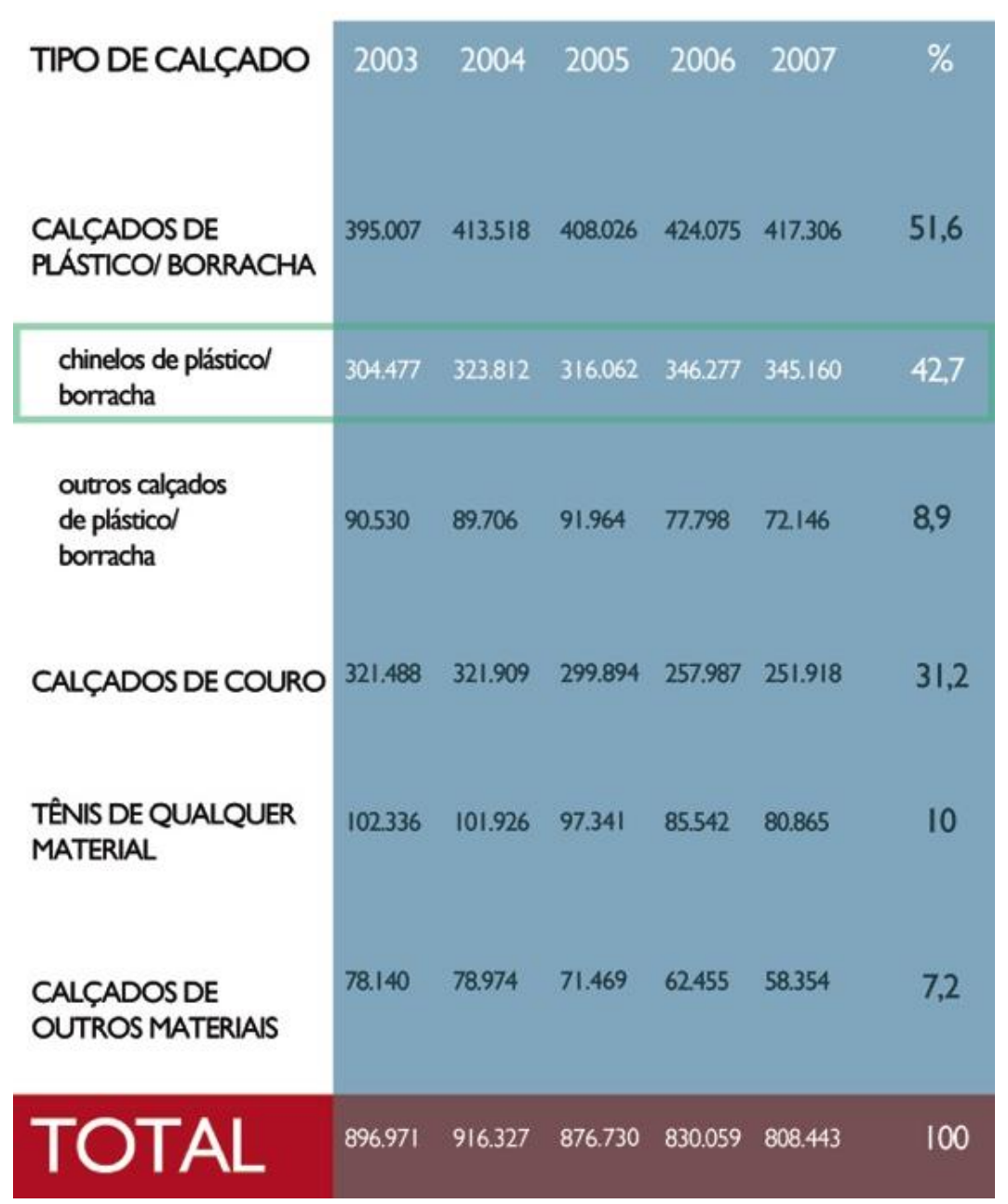

Fonte: RAIS [Brasil (2009)]

É possível notar que o Brasil possui grande destaque na produção de calçados e que sua produção é voltada principalmente para o mercado interno. Por um lado, isso mostra como o setor calçadista do Brasil possui capacidade de atender ao seu próprio público e suprir a necessidade por calçados. Mas por outro lado, sendo a maioria da produção destinada ao mercado interno, os impactos desta, as causas de uma gestão ruim dos resíduos e dos descartes dos produtos finais, refletem também internamente. Garlet (1998) corrobora mencionando que a produção calçadista brasileira é muito conhecida pelo seu destaque no mercado nacional e internacional, mas que esse setor também é muito conhecido pela geração de resíduos e pela falta da existência de programas para a reciclagem dos materiais que fazem parte desta cadeia.

$\mathrm{O}$ número de pesquisas com enfoque na reutilização de resíduos gerados no processo produtivo tem crescido devido ao aumento dos resíduos gerados pela indústria e a diminuição da área para a deposição desses dejetos (RAMASW et. al., 1983 apud GARLET, 1998).

Existem três principais motivos que estimulam o crescimento de pesquisas na área de reaproveitamento destes resíduos pela indústria como: o esgotamento dos pontos de origem da matéria-prima; preocupação com a preservação do meio ambiente; e necessidade de 
conseguir independência de matérias primas monopolizadas (petróleo) (CINCOTTO, 1990 apud GARLET, 1998).

Portanto, considerando fatores como: a defasagem da indústria da borracha no Brasil; a necessidade de repensar as estratégias de produção e descarte de matéria prima; o volume de produção de calçados, principalmente de chinelos de borracha bem como o descarte destes produtos e materiais no pós-uso; e ainda a necessidade de se obter alternativas menos impactantes nas fases de produção e utilização dos produtos pelo usuário, objetivou-se nesta pesquisa estudar a fase final do ciclo de vida da borracha, mais especificamente aquela referente aos chinelos, com o intuito de identificar formas viáveis de reciclagem deste material reinserindo-o no design de produtos. A justificativa para a escolha dos resíduos de chinelos se deu pela expressiva diferença entre o volume de produção de chinelos de borracha em relação aos demais tipos de calçados.

\section{Referencial Teórico}

\section{O Resíduo no Setor Calçadista}

Em se tratando do lixo gerado pelo setor calçadista, é preciso entender como essa situação acontece e quais seriam os motivos para não existir um tratamento para o lixo gerado pelos seus descartes.

O Brasil produz aproximadamente 76 milhões de toneladas de lixo por ano, e teria capacidade de reciclar cerca de 30\% do lixo produzido. Entretanto, apenas 3\% do lixo brasileiro são reciclados. Além disso, houve um crescimento de municípios que aderiram a programas sustentáveis, mas o total não atinge $20 \%$ das cidades brasileiras. Profissionais nos programas de reciclagem apontam para uma falta de integração entre os diversos setores da sociedade (PAIVA, 2015).

Além disso, dados de pesquisa realizada em 2015 pela Associação Brasileira de Empresas de Limpeza Pública e Resíduos Especiais - ABRELPE, sobre a gestão dos resíduos brasileiros, apontam crescimento alarmante da produção de resíduos. Entre os anos de 2003 a 2014 (período de abrangência da referida pesquisa) a produção de resíduos cresceu 29\% sendo que o crescimento populacional no mesmo período foi de $6 \%$. Outro dado importante foi o total de lixo destinado a aterros sanitários no Brasil, 58,4\%. Soma-se a isto o fato de que mais de 20 milhões de brasileiros não possuem um serviço de coleta regular de resíduos, já que $10 \%$ dos resíduos gerados não são nem recolhidos. Isso mostra que por mais que sejam criados programas de tratamento de lixo os mesmos não acompanham o crescimento da geração de resíduos pelos brasileiros (RIBEIRO, 2015).

Além disso, a diferença entre o crescimento do resíduo e o crescimento populacional mostra que o brasileiro tem consumido mais e isso somente evidencia a urgência da otimização do tratamento do lixo no Brasil; da interferência do designer para desenvolver produtos mais sustentáveis; e dos demais setores sociais e privados em estimular uma cultura sustentável no país (RIBEIRO, 2015).

Para a amenização do problema do lixo, o governo deve investir e incentivar medidas sustentáveis. Segundo a ABRELPE (2016), pouco se tem investido (cerca de $2 \%$ do PIB anual de 2014) na área de saneamento e infraestrutura. Isto diminui, consequentemente, as chances de criação de ferramentas que estimulem as mudanças e façam com que o grau de aceitação de medidas ambientais seja maior, conforme preconizam Manzini e Vezzoli (2005). Além disso, para que exista uma unificação no sistema de tratamento de resíduos sólidos brasileiro, o país deveria investir cerca de R\$ 11,6 bilhões até 2031 (ABRELPE, 2016). 
Conclui-se, de forma geral, que o Brasil ainda caminha lentamente em direção a um sistema de coleta sustentável. O caminho para uma melhor administração do resíduo e a adoção cada vez maior de uma consciência sustentável por parte da sociedade brasileira deve acontecer em um ciclo, onde todos os setores estão dispostos a adotar medidas para contribuir com isso.

Com o objetivo de aprofundar os conhecimentos sobre o destino do resíduo, foi realizada uma visita técnica ao aterro sanitário da Companhia de Saneamento do Paraná (SANEPAR) no município de Cianorte no Estado do Paraná, Brasil. A SANEPAR é a empresa responsável pela coleta de lixo e tratamento de resíduos sólidos no referido município. $\mathrm{O}$ aterro sanitário da cidade de Cianorte é exemplo nacional de tratamento do lixo, tendo iniciado suas atividades em 2002. Sua área total é de 15,54 ha e atende a aproximadamente 70 mil habitantes do município. Possui certificação ISO 31000 e NBR ISO 14001:2004, normas de excelência nacional com relação a tratamento de resíduos sólidos (SANEPAR, 2015). Marcio Benites era o responsável químico pelo aterro sanitário no momento da visita ${ }^{1}$.

Naquela oportunidade, houve esclarecimentos sobre o funcionamento e coleta de resíduos permeando aspectos referentes à coleta de resíduos sólidos, especificamente os chinelos de borracha. Segundo Benites um dos maiores problemas enfrentados é o lixo inadequado que chega ao aterro prejudicando todo o processo. Esse lixo pode ser: lixo reciclável, entulho e materiais de difícil decomposição ou que possuem destinos específicos após o descarte. Entre esses materiais está a borracha que possui tempo indeterminado de decomposição na natureza (BENITES, 2015).

Os resíduos de borracha são considerados resíduos sólidos. A NBR 10004, que classifica resíduos sólidos quanto as suas características para serem gerenciados de forma correta e com o mínimo de impacto no meio ambiente, menciona que os resíduos sólidos são todos aqueles sólidos ou semissólidos originários da indústria, atividades domésticas, hospitalares, comerciais, agrícolas e de serviço de varrição (ABNT, 2004). Estes resíduos são classificados como não perigosos quanto a sua toxidade em relação a organismos vivos.

Segundo a cartilha do Plano Nacional de Resíduos Sólidos (PNRS), elaborada pelo Governo Federal Brasileiro, o gerenciamento de resíduos sólidos deve ser realizado tanto pelas indústrias quanto pela população. Na cartilha percebe-se a preocupação com as questões ambientais e com o impacto ambiental dos resíduos gerados por toda a sociedade brasileira (ALMEIDA, 2014).

Dentre os objetivos do PNRS, estão (ALMEIDA, 2014):

- Preservação do meio ambiente e saúde do Brasil;

- Incentivar à prática de padrões sustentáveis na produção e no consumo;

- Diminuir o volume e a periculosidade de resíduos sólidos;

- Estimular a redução, reutilização, reciclagem e tratamento dos resíduos sólidos, além de criar destinos adequados aos resíduos.

Por fim, Benites incentiva a reciclagem de resíduos de chinelos descartados, já que os mesmos não são valorizados pelas cooperativas de reciclagem e nem são adequadamente descartados quando destinados a aterros. Porém, ressalta que a melhor forma de recolher as sandálias de borracha descartadas seria com a separação pela própria população como é feito com o lixo eletrônico, visto que o lixo que chega ao aterro não pode ser manuseado. Ressalta também que a separação pelo próprio usuário ou o recolhimento por alguma

\footnotetext{
${ }^{1}$ A visita técnica ao Aterro Sanitário de Cianorte - PR foi realizada no dia 01 de dezembro de 2015.
} 
entidade/cooperativa nas casas dos consumidores antes do produto ser jogado no lixo poderia ser uma ação mais econômica e saudável.

\section{Design e Sustentabilidade}

Para Manzini e Vezzoli (2005), o termo ecodesign liga a ação de projetar ao ambiente para o qual se projeta tornando a preocupação com o meio ambiente uma característica intrínseca a esse tipo de projeto. Somam-se a isto as dimensões sociais e econômicas que aproximam produtos e/ou serviços de soluções mais sustentáveis.

Mesmo sendo discutidas por diversas áreas, as noções de sustentabilidade e, mais especificamente na área de ciências sociais aplicadas, as noções de Design Sustentável muitas vezes são tratadas de forma superficial. Nota-se que há uma preocupação cada vez maior com o impacto causado no meio ambiente e tal preocupação torna necessária a criação de políticas mais limpas, tecnologias que agridam menos o meio ambiente, mas principalmente, mudanças culturais e, uma forma de favorecer esta mudança cultural é projetar produtos levando em conta tais questões. Manzini e Vezzoli (2005) dizem que apenas a criação de processos produtivos mais limpos e medidas paliativas, não são suficientes para que haja uma mudança profunda na sociedade em direção à sustentabilidade. São as transformações culturais e de valores que geram tais mudanças. Por isso, no longo prazo, as medidas devem ser um reflexo de uma mudança social e cultural. Existem quatro níveis de medidas a serem tomadas com relação ao ecodesign (MANZINI E VEZZOLI, 2005):

- No primeiro nível, o que acontece é uma mudança apenas na parte técnica dos produtos e serviços, como por exemplo, em seus materiais, a fim de otimizar o processo produtivo e lucro de vendas, fato que torna o produto competitivo diante do consumidor. Porém, o produto não possui impacto no aspecto cultural, visto que apenas componentes e processos produtivos são alterados. Esse nível é o mais explorado pela indústria e é conhecido como redesign;

- No segundo nível, os produtos e serviços são desenvolvidos desde o ponto inicial e projetados com foco na sustentabilidade e facilidade de aplicação, porém, existem poucas iniciativas com esta perspectiva. Alguns exemplos são os carros elétricos, alimentos, produtos corpóreos, etc. Estes produtos foram desenvolvidos atendendo à mudanças culturais rumo à sustentabilidade, mas sua capacidade de transformação cultural ainda é baixa;

- No terceiro nível, o desafio é grande para os projetistas e empresas, pois o produto ou serviço deve ser radicalmente sustentável e aceitável culturalmente. Produtos ou serviços como estes devem ser projetados de forma cautelosa, pois representam riscos. Por um lado se não aceitos socialmente, vão representar um prejuízo, mas se bem recebidos pelo usuário, eles possuem um diferencial natural contra todos os seus concorrentes. É possível ver que esse tipo de mudança requer muito empenho, mas são medidas que podem ser consideradas as mais congruentes com a sustentabilidade;

- O quarto nível diz respeito às mudanças socioculturais para criar novos cenários para o desenvolvimento sustentável. Isso pode ser feito por meio de pesquisas científicas no âmbito acadêmico e por empresas dispostas a se tornar transformadoras culturais.

Atualmente a indústria fica limitada aos dois primeiros níveis citados. Esses níveis são importantes para reduzir os impactos ambientais existentes, porém, para se atingir resultados mais sustentáveis, é preciso atingir níveis mais profundos que conduzam à transformações nos hábitos de consumo e mudanças socioculturais (MANZINI e VEZZOLI, 2005). 
Por outro ponto de vista, Cardoso (2013) menciona que o acúmulo do lixo é um reflexo de como a sociedade em geral trata os artefatos e que a significação de um objeto pode ser algo muito instável. Uma comparação interessante seria entre as embalagens e um automóvel. Ambos os produtos passaram por um processo de design, porém, o significado e valor agregado que são impressos nestes produtos alteram o modo como tratamos os mesmos. $\mathrm{O}$ designer tem um papel de ressignificador dos objetos descartados. O ponto principal ao qual o designer tem poder é em dar significados aos artefatos, materiais e processos. Pode-se concluir que o designer é responsável por alterar a visão do que é considerado lixo (CARDOSO, 2013).

Por fim, esta pesquisa procurou reaproveitar um resíduo, considerado sem valor pela sociedade e sem consenso de qual a destinação correta, no desenvolvimento de um novo material passível de utilização pelo design de produtos. Neste sentido, propôs-se agregar valor ao resíduo da borracha de chinelos descartados por meio da criação de um novo material, projetando novos significados e soluções para o problema dos resíduos de borracha.

\section{Método de Pesquisa}

De acordo com Gil (1999, p.33), esta pesquisa possui Método Experimental por que submete "objetos de estudo à influência de certas variáveis, em condições controladas e conhecidas pelo investigador". Além disso, pode ser classificada como exploratória e aplicada, pois explora resultados aproximados de um tema ainda pouco explorado, bem como seus resultados podem ser aplicados em situações reais.

Para a execução da pesquisa, foram definidas 8 etapas de trabalho, as quais estão resumidas no infográfico a seguir: 
Figura 4 - Visão Geral do Método de Pesquisa em 8 passos.

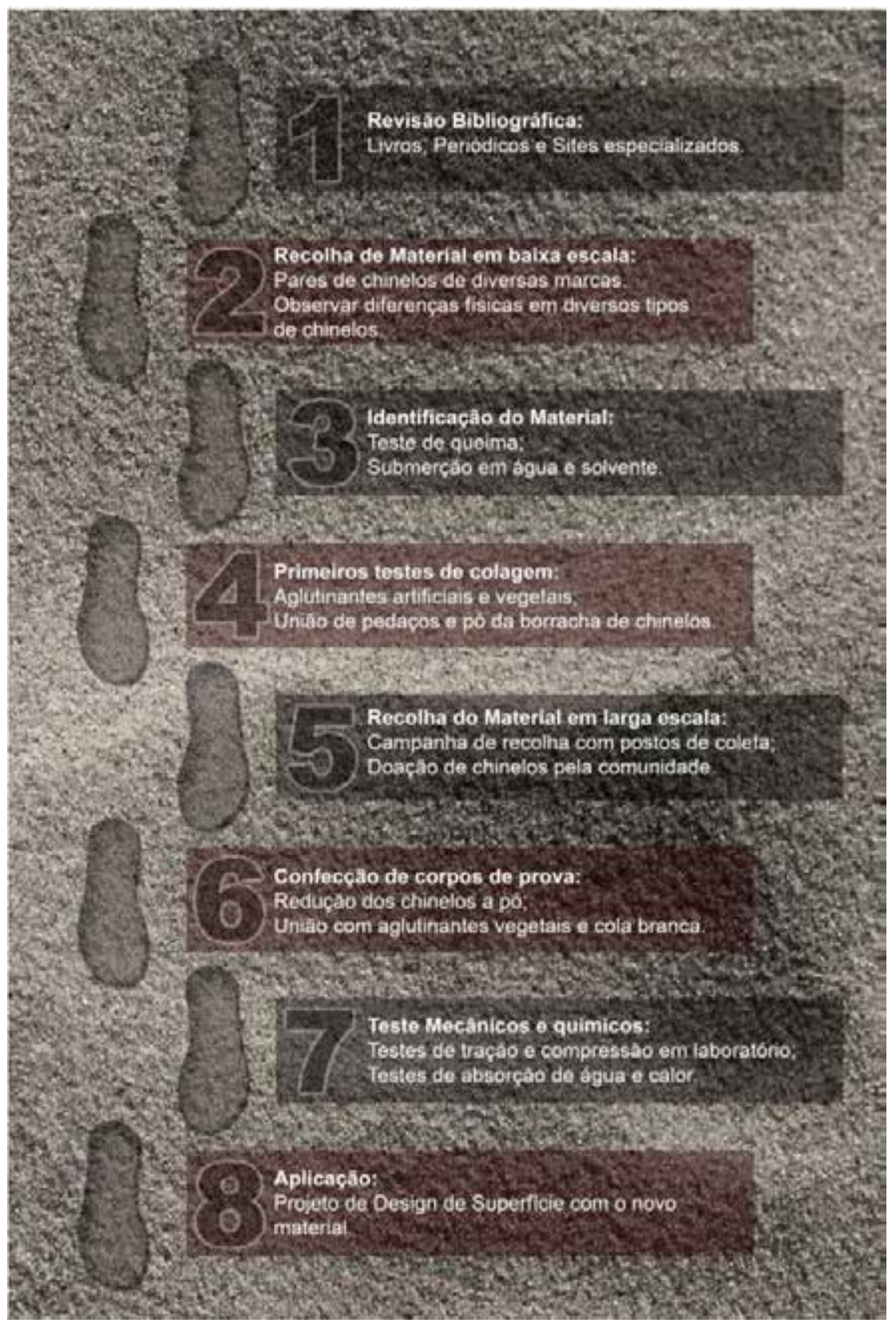

Fonte: Elaborado pelos autores.

Para melhor compreensão, nos parágrafos seguintes são explicados os objetivos de cada etapa e quais seus principais resultados almejados.

A primeira etapa consistiu da Revisão Bibliográfica acerca de dados sobre a indústria da borracha e calçadista, bem como, aspectos inerentes ao Design Sustentável e a esta pesquisa. Foi realizada Revisão Bibliográfica Simples em livros, periódicos e sites especializados.

A etapa seguinte culminou na primeira Recolha de Material, em baixa escala, com o intuito de observar diferenças físicas entre chinelos de borracha de marcas diferentes. $\mathrm{O}$ 
objetivo foi adquirir material para apoiar as etapas seguintes no que concerne a diferenciação dos materiais em diversos tipos/marcas de chinelos, na intenção de padronizar os resíduos de borracha pesquisados. A recolha ocorreu em um condomínio onde os moradores deixavam os chinelos em um ponto de coleta. Como resultado, esperava-se pelo menos recolher chinelos das duas principais marcas vendidas no Brasil .

A etapa de número três compreendeu a Identificação dos Materiais por meio da observação do comportamento mediante queima e submersão em água e solvente. O objetivo foi detectar congruências químicas e físicas nos resíduos de chinelos de duas marcas no intuito de compreender se seria possível utilizar os diversos tipos de resíduos gerados pela sociedade por meio dos chinelos de borracha descartados. Além disso, os resíduos foram comparados com amostras pré-concebidas constituídas por "pó de borracha de chinelo da marca Havaiana + cola branca". O processo de identificação por queima dos materiais ocorreu por observação da cor da chama, consequências da queima no material (carbonização, gotejamento, aborbulhamento), presença e cor da fumaça, presença de fuligem, tempo de queima e cheiro. Como instrumento de confirmação, foram utilizados os preceitos de Lima (2006).

$\mathrm{Na}$ quarta etapa foram realizados os Primeiros Testes de Colagem dos resíduos. O objetivo foi juntar os resíduos para a produção de placas de borracha. Vários testes foram propostos nesta etapa, os quais propunham a utilização de aglutinantes artificiais e de origem vegetal na união de pedaços da borracha do chinelo; pedaços de chinelos com pó da borracha do chinelo; e somente pó da borracha do chinelo. Entre os aglutinantes artificiais testados foram utilizados cola branca da marca Cascorez, cola epóxi da marca Araudite, cola de silicone da marca TekVed e gesso. Os aglutinantes de base vegetal testados foram o poliuretano vegetal da marca Imperveg, o aglutinante bi componente da marca Kehl e o aglutinante ecológico à base d'água da marca Adespec. Este artigo apresentará apenas os resultados obtidos com o aglutinante da marca Kehl.

A quinta etapa consistiu da Recolha do material em larga escala. O objetivo desta foi recolher quantidade suficiente de material para confecção de corpos de prova de três materiais experimentais. Esta etapa envolveu a comunidade no projeto e promoveu a conscientização dos usuários de chinelos de borracha sobre o ciclo de vida do produto e da possibilidade de descarte adequado. Foi realizada campanha de coleta de chinelos em um campus universitário e promovido por meio de rede social, cartazes e postos de coleta distribuídos pelo campus.

$\mathrm{Na}$ sequência, foi proposto a redução a pó dos chinelos da marca "Havaianas"2 para a Confecção de Corpos de Prova. Buscou-se utilizar somente aglutinantes vegetais e cola branca no intuito de minimizar os impactos ambientais futuros e o objetivo da etapa foi realizar testes de resistência física e química controlados, tais como de resistência à tração e compressão, bem como de absorção de água e de temperatura.

Em laboratório específico para testes de materiais, a sétima etapa consistiu justamente dos Testes Mecânicos de tração e compressão com os novos materiais. O intuito foi identificar as principais características e propriedades dos novos materiais com objetivo de se obter dados para indicar possíveis aplicações do material em produtos de design. Utilizou-se

\footnotetext{
${ }^{2}$ Os chinelos da marca "Havaianas" foram os mais coletados durante as campanhas. Em pesquisa realizada pelos autores com usuários de chinelos de borracha, cerca de $85 \%$ dos usuários preferem esta marca, o que levou esta pesquisa a realizar testes mecânicos somente com amostras confeccionadas com este resíduo específico, além de que seu comportamento no processo de redução a pó ocorre de maneira diferente dos resíduos de outras marcas.
} 
como equipamento o Sistema Universal para testes de tração, compressão e flexão da marca EMIC constituído por Máquina Universal Série 23 e Estrutura de $2.000 \mathrm{kN}$.

A última etapa consistiu de um processo de design que sugeriu a aplicação do novo material um produto.

No capítulo seguinte será apresentado e discutido apenas recorte dos resultados obtidos, Em outras palavras, somente àqueles obtidos pela amostra (corpo de prova) que utilizou o aglutinante bi componente da marca Kehl. Esta foi a que apresentou os melhores resultados nos testes mecânicos.

\section{Resultados e Discussões}

O aglutinante bi componente da marca KEHL possui em sua composição, componentes renováveis como óleos de origem vegetal que não causam impactos negativos no meio ambiente (KEHL, 2016). A empresa Kehl atuou como parceira fornecendo os aglutinantes para o projeto.

Após vários testes foi possível verificar que a concentração que promove um melhor resultado compreende volumes iguais dos componentes, por exemplo, uma medida de pó de borracha e uma medida do aglutinante. A secagem ocorre rapidamente após expansão do material. O material resultante é poroso, leve, com densidade de $0,5 \mathrm{~g} / \mathrm{cm}$ e resistente. A coloração do aglutinante, de cor marrom claro, afeta sutilmente o resultado visual do material final, de acordo com a cor de borracha que se utiliza (Figura 5).

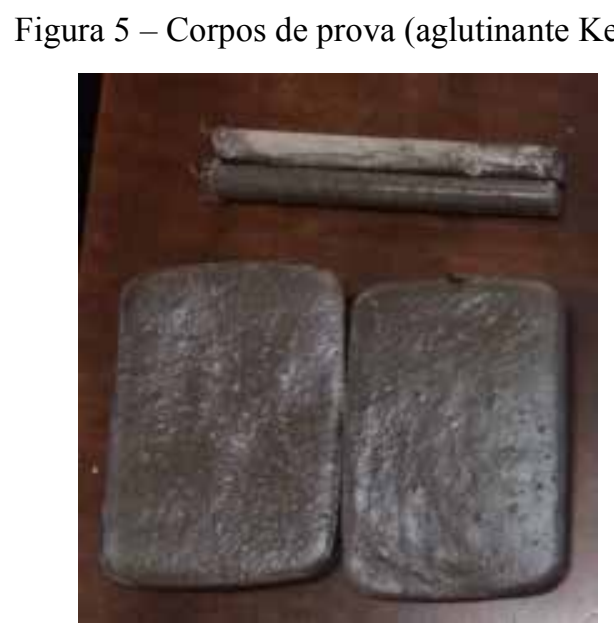

Fonte: Elaborado pelos autores.

Foram realizados ensaios de tração e compressão com amostras do material. No teste de tração, a amostra cilíndrica com aglutinante Kehl suportou uma força máxima de $1180 \mathrm{~N}$ e teve um alongamento de $4,11 \%$ até a ruptura. É possível que a presença de bolhas de ar na estrutura interna do material tenha comprometido sua resistência. No teste de compressão foi constatado que a amostra em forma de paralelepípedo com $20 \mathrm{~cm}$ de altura, $10 \mathrm{~cm}$ de comprimento e $2 \mathrm{~cm}$ de espessura suportou até $10543,45 \mathrm{~N}$ o que equivale a $1075,8 \mathrm{~kg}$.

Em teste hidroscópico, a amostra de 97 gramas ficou submersa em água por 24 horas, sendo que neste período, seu peso aumentou em 1 grama, demonstrando baixa capacidade de absorção mesmo sendo um material bastante poroso.

Comparado a outros materiais já conhecidos, este material experimental se assemelha ao poliuretano expandido, em densidade e possibilidades de aplicação. Ainda assim, vale 
lembrar que a composição do aglutinante tem origem vegetal e é de baixo impacto ambiental, amenizando agressões por substâncias voláteis e por componentes artificiais. Além disso, utiliza na composição o resíduo de borracha sem possibilidade de descarte definida e, convencionalmente, baixa probabilidade de reciclagem.

\section{Proposição de Aplicação em Design de Superfície}

Por meio de um brainstorming, verificaram-se várias possibilidades de aplicação do material desenvolvido tais como: material para vedação, blocos para prototipagem, joias, piso antiderrapante, revestimento decorativo, móveis, painéis e estruturas pré-moldadas, materiais para construção, mobiliário interno e externo, objetos em geral e módulos para jardim suspenso. Para esta pesquisa, optou-se por utilizar este material experimental em um processo de design para desenvolver um revestimento de parede. As cores presentes nos resíduos de chinelos, a possibilidade de exploração de formas, padrões e relevos, bem como a leveza do material foram os fatores que definiram sua aplicação como revestimento.

Dentro do processo de design, utilizaram-se como inspiração a identidade do próprio design brasileiro e a cultura nacional. Além disso, o resíduo utilizado no material era proveniente de chinelos da marca Havaianas, mundialmente conhecidos pela identidade brasileira intrínseca ao produto. O painel semântico da Figura 6 ilustra os aspectos visuais e simbólicos inerentes ao referido projeto.

Figura 6 - Painel semântico sobre aspectos culturais brasileiros.

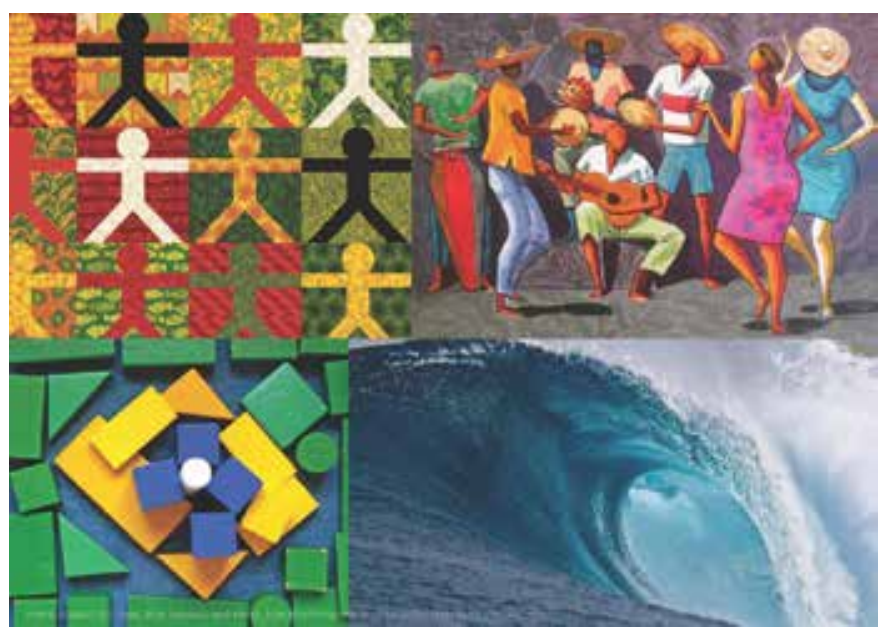

Fonte: Ortiz (2016).

O revestimento foi desenvolvido tendo como base elementos que lembram o Brasil, como o movimento das ondas, samba, a vibrante cultura brasileira e as paisagens brasileiras em geral. O resultado foi um módulo quadrado, que permite diferentes composições de acordo com a necessidade do usuário (Figura 7). 
Figura 7 - Revestimento de Parede "ONDA".

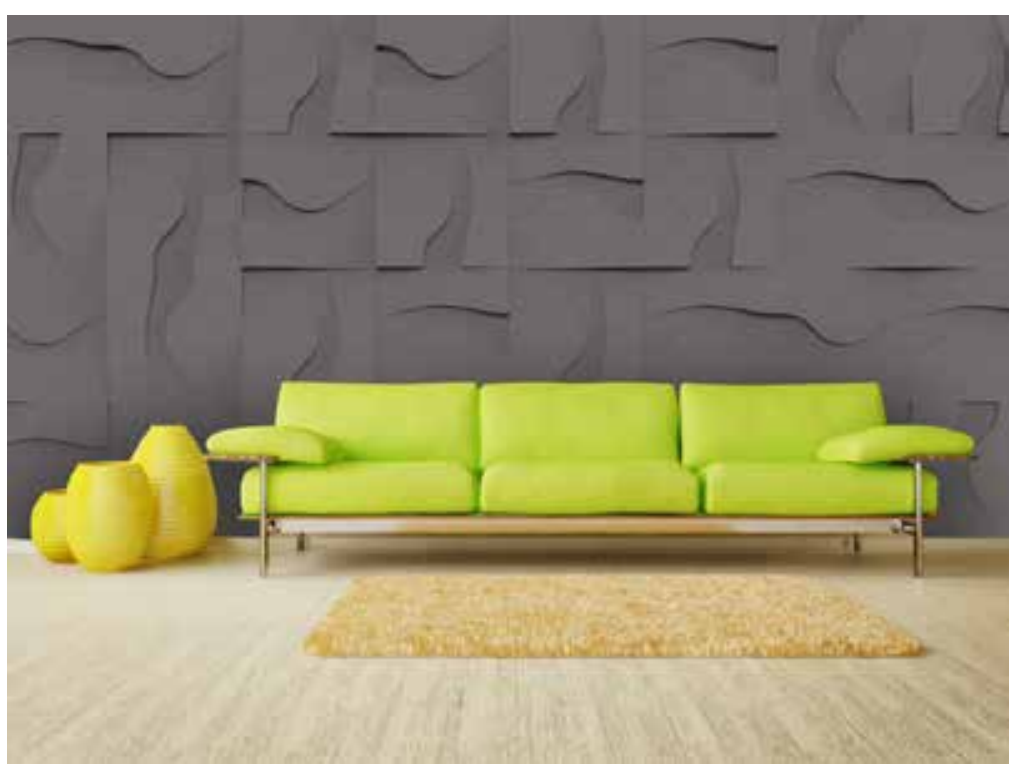

Fonte: Ortiz (2016).

A solução propõe uma alternativa para a reciclagem dos chinelos de borracha descartados, sendo que essa abordagem pode ser adotada no final do ciclo de vida destes produtos, prolongando, portanto, a utilização deste material pelo mercado.

\section{Conclusão}

Como já mencionado o designer tem um papel de ressignificador dos objetos e materiais. Esta pesquisa sugeriu agregar valor a um resíduo que era e é erroneamente descartado pela população e que não é aproveitado pelas empresas de coleta. Diante do caráter desafiador deste projeto, muitas etapas ainda devem ser cumpridas para que os materiais propostos sejam realmente viáveis.

Com os resultados obtidos, pode-se mostrar que o designer também tem um papel de transformador social, ambiental e econômico. O design sustentável propõe que o profissional possa olhar com maior afinco todo o ciclo de vida de um produto, projetando para que tudo possa resultar em um menor impacto ambiental e influenciar até mesmo o comportamento do usuário incentivando-o a praticar o descarte de forma mais correta e consciente.

O material proposto ainda está em fase de desenvolvimento. Sugere-se para trabalhos futuros identificar alternativas para diminuir a quantidade e tamanho de bolhas de ar no material aumentando assim sua resistência. São necessários novos ensaios, com corpos de prova mais precisos e confeccionados de maneira mais apropriada. Além disso, é importante que se faça novos estudos para identificar outras possibilidades de composição com este resíduo, tais como: novos aglutinantes; novas formas de entrada da borracha (grânulos, pedaços de diversos tamanhos); identificar outras estratégias para a transformação da borracha, que utilize pouca energia elétrica e esforços humanos; fazer uma análise do impacto ambiental dos novos materiais; e avaliar as capacidades térmicas e acústicas dos materiais desenvolvidos.

Enfim, os resultados aqui apresentados não devem ser tomados como única solução para o resíduo de chinelos descartados. No entanto, sugerem que esta iniciativa possa ser 
tomada como inspiração para um processo de ideação para outras experiências que, como relatam McDonough e Braungart (2002), possa entender o design com um processo de projeto "do berço ao berço".

\section{Referências}

ASSOCIAÇÃO BRASILEIRA DE NORMAS TÉCNICAS. NBR 10004: Resíduos sólidos Classificação. Rio de Janeiro: ABNT, 2004. 77 p. Disponível em: $<$ http://www.videverde.com.br/docs/NBR-n-10004-2004.pdf $>$. Acesso em: 31 jan. 2016.

ABRELPE. Estimativa dos Custos para Viabilizar a Universalização da Destinação Adequada de Resíduos Sólidos no Brasil. Disponível em: $<$ http://www.abrelpe.org.br/estudo_apresentacao.cfm>. Acesso em: 18 maio 2016.

ALMEIDA, Ana Carla. Plano de Resíduos Sólidos: Responsabilidade Socioambiental na Administração Pública. Brasília: Secretaria de Articulação Institucional e Cidadania Ambiental, $2014 . \quad 64 \quad$ p. Disponívelem: $<$ http://www.comprasgovernamentais.gov.br/arquivos/cartilhas/cartilha_pgrs_ mma.pdf $>$. Acesso em: 31 jan. 2016.

BENITES, Marcio. Visita ao aterro sanitário da SANEPAR. [dec. 2015]. Entrevistador: ORTIZ, Guilherme: Universidade Estadual de Maringá, 2015.

BRASIL. MINISTÉRIO DO TRABALHO E EMPREGO. Bases estatísticas RAIS/ Caged. Disponível em: <http://sgt.caged.gov.br/index.asp>. Acesso em: 14.12.2009.

CARDOSO, Rafael. Design para um mundo complexo. São Paulo: Cosacnaify, 2013. 262 p.

ORTIZ, Guilherme Clausem. Reutilização da borracha sintética de chinelos descartados no design de produtos. 2016. 198 f. Monografia (Graduação) - Curso de Design, Universidade Estadual de Maringá, Cianorte, 2016.

FORREST, Martin. Recycling and Re-use of Waste Rubber. [s.i.]: Smithers Rapra Technology, 2014. Cap. 3. p. 17-30. Disponível em: $<$ http://www.smithersrapra.com/SmithersRapra/media/Sample-Chapters/Recycling-and-Reuse-of-Waste-Rubber.pdf>. Acesso em: 31 jan. 2016.

GARLET, Givanildo. Aproveitamento de Resíduos de E.V.A. (Ethylene Vinyl Acetate) como agregado para concreto leve na construção civil. 1998. 162 f. Dissertação (Mestrado) - Curso de Engenharia Civil, Universidade Federal do Rio Grande do Sul, Porto Alegre, 1998. Disponível em: $<$ https://www.lume.ufrgs.br/bitstream/handle/10183/118243/000226272.pdf?sequence=1 $>$ . Acesso em: 26 jan. 2016.

GIL, Antônio Carlos. Métodos e técnicas de pesquisa social. São Paulo: Atlas, 1999. 
GLOBALRUBERMARKETS. SBR will reach 141.5 billion yuan trading. 2014. Disponível em: <http://globalrubbermarkets.com/19138/sbr-will-reach-141-5-billion-yuan-trading.html>. Acesso em: 28 jan. 2016.

GUIDOLIN, Silvia Maria; ROCHA, Érico Rial Pinto da; COSTA, Ana Cristina Rodrigues da. BNDES: Indústria calçadista e estratégias de fortalecimento da competitividade. 2010. Disponível em: $<$ http://www.bndes.gov.br/SiteBNDES/export/sites/default/bndes_pt/Galerias/Arquivos/conhe cimento/bnset/set3104.pdf>. Acesso em: 1 mar. 2016.

IMPERVEG. Família de Resinas. Disponível em: <http://imperveg.com.br>. Acesso em: 06 jul. 2016.

KEHL. Aglomerantes. Disponível em: $<$ http://www.kehl.ind.br/poliuretanos.php?opcao=agl>. Acesso em: 07 jul. 2016.

LIMA, Marco Antonio Magalhães. Introdução aos Materiais e Processos para Designers. Rio de Janeiro: Editora Ciência Moderna, 2006. 225 p.

MANZINI, Ezio; VEZZOLI, Carlo. O Desenvolvimento de Produtos Sustentáveis. São Paulo: Editora da Universidade de São Paulo, 2005. 345 p.

MCDONOUGH, William; BRAUNGART, Michael. Cradle to Cradle: Remaking the way we make things. New York: North Point Press, 2002.

MUCAMBO. Um pouco da História da Borracha. São Paulo, 2015. Disponível em: < http://www.mucambo.com.br/pdfs/historiadaborracha.pdf >. Acesso em: 19 jan. 2016.

NUNES, Ilson. A Reciclagem da Borracha: entrevista. 2015. São Paulo: Revista Borracha Atual. Entrevista concedida à Associação Brasileira de Tecnologia da Borracha (ABTB).

PAIVA, Roberto. Apenas 3\% de todo o lixo produzido no Brasil é reciclado. 2015. Disponível em: <http:/g1.globo.com/jornal-hoje/noticia/2015/04/apenas-3-de-todo-o-lixoproduzido-no-brasil-e-reciclado.html>. Acesso em: 18 maio 2015.

PAPAUTSKY, David. Borracha: Recuperação e Regeneração. São Paulo: Ponto Quatro, 2003.

RIBEIRO, Stênio. Produção de lixo no país cresce $29 \%$ em 11 anos, mostra pesquisa. 2015. Disponível em: <http://agenciabrasil.ebc.com.br/geral/noticia/2015-07/producao-delixo-no-pais-cresce-29-em-11-anos-mostra-pesquisa-da-abrelpe>. Acesso em: 18 maio 2015.

SANEPAR. Aterro sanitário de Cianorte. Cianorte, Paraná. 2015.

STATISTA. Global consumption of natural and synthetic rubber from 1990 to 2015 (in 1,000 metric tons). Disponível em: $<$ http://www.statista.com/statistics/275399/worldconsumption-of-natural-and-synthetic-caoutchouc/>. Acesso em: 27 jan. 2016. 